\title{
CCR5- $\Delta 32$ genetic polymorphism associated with benign clinical course and magnetic resonance imaging findings in Brazilian patients with multiple sclerosis
}

\author{
DAMACIO RAMÓN KAIMEN-MACIEL ${ }^{1,2}$, EDNA MARIA VISSOCI REICHE ${ }^{3}$, \\ DORALINA GUIMARÃES BRUM SOUZA ${ }^{4}$, ELISABETH REGINA FROTA COMINI ${ }^{5}$, FLAVIO BOBROFF ${ }^{2}$, \\ HELENA KAMINAMI MORIMOTO ${ }^{3}$, MARIA ANGÉLICA EHARA WATANABE ${ }^{6}$, \\ JAQUELINE CARVALHO DE OLIVEIRA ${ }^{6}$, TIEMI MATSUO ${ }^{7}$, \\ JOSIANE LOPES ${ }^{2}$ and EDUARDO ANTONIO DONADI ${ }^{4}$

\begin{abstract}
${ }^{1}$ Department of Clinical Medicine, Health Sciences Center, and ${ }^{2}$ Outpatient Clinic for Multiple Sclerosis of University Hospital, State University of Londrina, Londrina, Paraná; ${ }^{3}$ Department of Pathology, Clinical Analysis, and Toxicology, Health Sciences Center, ${ }^{4}$ School of Medicine of Ribeirão Preto, University of São Paulo, ${ }^{6}$ Department of Pathological Sciences, Biological Sciences Center, and ${ }^{7}$ Department of Biostatistics, Exacts Sciences Center, State University of Londrina, Londrina, Londrina, Paraná, Brazil
\end{abstract} \\ Ribeirão Preto, São Paulo; ${ }^{5}$ School of Medicine, Federal University of Minas Gerais, Belo Horizonte, Minas Gerais;
}

Received March 30, 2007; Accepted May 4, 2007

\begin{abstract}
The CCR5 chemokine receptor has been implicated in the pathogenesis of multiple sclerosis (MS). This research was carried out to investigate the association between the CCR5- $\triangle 32$ deletion in 124 patients with MS from Southern Brazil. Ninety-eight $(79.0 \%)$ patients presented with relapsingremitting MS (RR-MS), 17 (13.7\%) secondary progressive MS (SP-MS), 8 (6.5\%) primary progressive MS (PP-MS) and one $(0.8 \%)$ clinically isolated syndrome (CIS). The control group consisted of 127 healthy blood donors from the same geographic region. The disease severity was assessed clinically using the Expanded Disability Status Scale (EDSS). Genomic DNA was extracted from peripheral blood cells and the genetic polymorphism was evaluated by polymerase chain reaction. Of the MS patients, $85(68.5 \%)$ were females ( $\mathrm{p}=0.0093)$. The CCR5- $\Delta 32$ frequency among the controls was $5.5 \%$, and did not differ from that observed among the MS patients $(4.8 \%)$ $(\mathrm{p}=0.7337)$. The mean $( \pm \mathrm{SD})$ age at disease onset among the carriers and non-carriers of the CCR5- $\Delta 32$ allele was 31.7 $( \pm 11.1)$ and $36.6( \pm 12.0)$ years, respectively $(\mathrm{p}=0.1312)$. The duration $( \pm \mathrm{SD})$ of the disease was $11.2( \pm 12.9)$ and $7.7( \pm 5.6)$
\end{abstract}

Correspondence to: Dr Edna Maria Vissoci Reiche, Department of Pathology, Clinical Analysis, and Toxicology, Health Sciences Center, University Hospital, State University of Londrina, Av. Robert Koch 60, Vila Operária, CEP 83038-440, Londrina, Paraná, Brazil E-mail: reiche@sercomtel.com.br

Key words: multiple sclerosis, CCR5- $\Delta 32$ polymorphism, chemokine receptor years among the CCR5- $\triangle 32$ heterozygous, and CCR5 wild type, respectively $(\mathrm{p}=0.396)$. The mean $( \pm \mathrm{SD})$ EDSS among the MS patients carriers and non-carriers of the CCR5- $\triangle 32$ allele was $2.4 \pm 1.2$ and $2.67 \pm 2.2$, respectively $(\mathrm{p}=0.9796)$ The MRI findings in MS patients with the CCR5- $\triangle 32$ genotype exhibited lower positive gadolinium enhancing-imaging $(p=0.0013)$ and lower brain atrophy $(p=0.1333)$ than MS patients with the CCR5 wild-type genotype. Despite that the differences were not significant, the results suggested that the disease onset and progression to disability may be prolonged in MS carriers of CCR5- $\Delta 32$, and CCR5- $\Delta 32$ could be considered a favorable prognostic biomarker of MS. Further studies comprising larger numbers of individuals carrying non-wild-type haplotypes are needed to determine CCR5$\Delta 32$ involvement in the specific process of MS pathology and pathogenesis.

\section{Introduction}

Multiple sclerosis (MS) is a chronic disorder of the central nervous system (CNS) characterized by inflammation, demyelination, axonal damage and repair mechanisms. The disease is multifactorial, complex, and autoimmune, which mainly affects young people and causes progressive and relapsing neurologic incapacity. It is the most common demyelinating disease, clinically important in humans, and affects women approximately twice as often as men (1).

In addition to the broad clinical spectrum of the MS, there is also heterogeneity in the morphological alterations of the brain found by magnetic resonance imaging (MRI) (2) and histopathological evaluation, as well as in clinical presentation, the CNS systems and areas that are primarily affected and the therapy response $(3,4)$. 
The etiology of MS remains unclear, probably develops in genetically susceptible individuals and may require additional environmental triggers. Among putative environmental factors, both infectious agents, herpesvirus and retroviruses, and behavioral or lifestyle influences have been proposed to induce or contribute to disease expression (5). MS is still considered a CD4 ${ }^{+}$Th1-mediated autoimmune disease and it is believed to result from a complex interaction of a number of genes each with modest effect. The association of human leukocyte antigen (HLA) class I and class II alleles with MS has been extensively studied (1).

Proinflammatory cytokines (IFN- $\gamma, \mathrm{TNF}-\alpha, \mathrm{IL}-12$, IL-7, and IL-23), anti-inflammatory cytokines (IL-4, IL-10), and others exerting both effects (IL-6) are involved in the pathogenesis of MS at different points $(1,6-7)$. Different pairs of chemokine receptors and their ligands seem also to play a pathogenic role in MS by activation and directional migration of cells to sites of CNS inflammation. Among them there are CXCR3 and CXCL9, CXCL10; CCR1 and CCL3 (MIP-1a), CCL4 (MIP1b), CCL5 (Regulated by Activation Normal T-cells Expressed and Secreted - RANTES); CCR2 and CCL2; CCR5 and CCL3, CCL4, CCL5. Interfering with the chemokine system may be an effective therapeutic approach in MS (8-9).

Chemokines induce and activate leukocyte adhesion molecules, such as integrins of the b1 subfamily (mainly a4b1), as well as leukocyte integrins and adhesion receptors of the immunoglobulin superfamily (ICAM 1, VCAM 1). Both are the main molecules involved in the MS pathogenesis and establish a chemotactic concentration that results in recruitment across the endothelium monolayer (10). The induction of proteolytic enzymes such as matrix metalloproteinases (MMP) facilitates blood-brain-barriers (BBB) opening, and subsequently chemokines mediate retention of leukocytes in the CNS (11). High cerebrospinal fluid (CSF) levels of MMP-9 activity were associated with the recurrent disease activity (12).

Among the various chemokine receptors, CCR5 and CXCR3 have received attention as key receptors on Th1 cells, as have CCR3 and CCR4 on Th2 cells (1). The expression of receptor CCR5, as well as of its ligand the chemokine CCL5, CCL3 and CCL4, has been consistently observed in the brain and in the LCR of patients with MS (13). Chemokine receptors expressed by Th1 cells may be important in MS, as increased IFN- $\gamma$ precedes clinical attacks. A study showed that CXCR3 ${ }^{+}$ $\mathrm{T}$ cells are increased in blood of relapsing-remitting (RR)$\mathrm{MS}$, and both $\mathrm{CCR}^{+}$and $\mathrm{CXCR}^{+} \mathrm{T}$ cells are increased in secondary progressive (SP)-MS compared with controls . Furthermore, peripheral blood CCR5 ${ }^{+} \mathrm{T}$ cells secreted high levels of IFN- $\gamma$. Areas of plaque formation were infiltrated by CCR5-expressing and, to a lower extent, CXCR3-expressing cells. These results provide a rationale for the use of agents that block CCR5 and/or CXCR3 as a therapeutic approach in the treatment of MS (14).

Genetic polymorphisms in the cytokines, chemokines and their receptors have been associated with the susceptibility or resistance to various diseases, or to clinical disease variables, although definitive evidence is still lacking. Most chemokine genes are encoded in a cluster on chromosome 17q11.2-12, which has been identified in a number of genome-wide screens as being potentially associated with MS (15). Polymorphism of CCR2, IL-10 receptor $\alpha$, and Fas-L may confer protective effects for MS; and polymorphism of CCR5, IL-10, IL-4 receptor $\alpha$, IL- 2 receptor $\beta, \mathrm{IFN}-\gamma$, vitamin $\mathrm{D}$, and estrogen receptor confer risk to MS (1). However, genetic studies carried out on MS patients from different worldwide populations have shown conflicting results (16-21).

The homozygous deletion of 32 base-pair in the CCR5 gene, named CCR5- $\Delta 32$, results in failure to express the receptor on the cell surface, while the CCR5- $\Delta 32$ heterozygous carriers express less receptor than wild-type homozygotes (22). This first study demonstrated that $15 \%$ to $20 \%$ of the Caucasians were heterozygous for the allele CCR5- $\triangle 32$ and $1 \%$ or less was homozygous. Posterior studies demonstrated that the allele CCR5- $\Delta 32$ was found in approximately $10 \%$ of the population of European descendants. Outside Europe, CCR5- $\triangle 32$ is seen at very low frequencies in Asian, Saudi Arabian, Indian and Pakistani populations, and is virtually absent in native populations from sub-Saharan Africa, Oceania and the Americas (23-26).

The global, regional, and ethnic distributions of frequency of the CCR5- $\triangle 32$ allele vary significantly, ranging from $16 \%$ in Finnish populations to the lowest $2.1 \%$ in Sardinia $(25,27$ $29)$. The heterozygous and homozygous allele frequencies in Caucasian populations of Western European origin are $18 \%$ and $1 \%$ respectively (30-32). The CCR5- $\Delta 32$ mutation leads to a nonfunctional receptor that has been associated with decreased severity of MS. Although homozygous individuals for CCR5- $\Delta 32$ were not protected from MS, heterozygosity for this deletion has been associated to prolonged diseasefree intervals and a delay in MS onset and with a lower risk of recurrent clinical disease activity (12). Results obtained in another study also confirm that the genotype CCR5- $\Delta 32$ could modulate the severity in MS, resulting in less inflammation and tissue destruction (33).

Genetic analysis of the chromosome 3p21-24 region and the CCR5 and CCR2B loci showed no evidence of linkage to MS for both tested markers. However, age onset was approximately 3 years later in patients carrying the CCR5- $\Delta 32$ deletion, after controlling for gender effects. The authors concluded that the chemokine receptor expression may be associated with differential disease onset in a subset of patients and may provide a therapeutic target to modulate inflammatory demyelination (34).

A study reported an interaction between CCR5- $\Delta 32$ and MS in Israeli patients (35). Of 256 patients with MS, 2.3\% were homozygous for CCR5- $\Delta 32,10.2 \%$ were heterozygous, and $87.5 \%$ had the CCR5 wild-type genotype. The CCR5$\triangle 32$ allele frequency was $7.4 \%$, similar to that reported in the general Israeli population. Progression to disability was prolonged in CCR5- $\Delta 32$ homozygous and heterozygous MS patients compared with those with the CCR5 wild-type genotype, suggesting that this allele may be considered a favorable prognostic factor in MS.

Other CCR5 genetic polymorphism studies carried out in MS patients reported contradictory results, with no significant difference in the allelic frequency of CCR5- $\Delta 32$ between the MS patients and the control group, and the presence of CCR5$\Delta 32$ homozygous patients among the MS patients indicated that the absence of CCR5 is not protective against MS (36-37).

No significant difference in distribution of the CCR5- $\triangle 32$ allele was observed between the 331 RR-MS and SP-MS 
patients and controls, between the 108 primary progressive (PP)-MS patients and controls or between the PP-MS and RR/SP-MS groups. Furthermore, no differences in rate of disease progression were detected between carriers and noncarriers of the mutated allele. In the population-based group of RR/SP-MS patients, carriage of the CCR5- $\triangle 32$ allele was associated with a lower age at disease onset. However, no significant differences in age of onset were present in the PP-MS group or in a second RR-MS population, suggesting that the CCR5 genotypes are not a major determinant of susceptibility to develop MS in the population studied (38).

Conflicting results with the previously reported association between CCR5- $\Delta 32$ carriage and a better prognosis were observed. An increased frequency of CCR5- $\Delta 32$ allele was found to be associated with early death, suggesting that MS patients with the deletion have twice the mortality rate of patients with the normal genotype (39).

MS in Brazil. Epidemiological data from Brazil show that prevalence of MS is variable, being more frequent in the Southern and Southeastern areas of the country, rather than in the Northern and Northeastern regions (40). In the Northern region of the State of Pernambuco, the prevalence of MS was equal to 1.36:100,000 inhabitants (41). In the Southern region, particularly in Londrina, State of Paraná, the prevalence of MS was 14:100,000 inhabitants (42). When the populations from Southern and Southeastern regions were studied, it was observed that the profile of the MS patients seems to be more similar to patients from the Northern hemisphere than to those whose African-Brazilian admixture is predominant (43).

A cross-sectional study of clinical and epidemiological profiles of MS in patients from the State of Bahia, in the Northeastern region, reported higher frequency in mulatto individuals $(64.0 \%)$, and RR-MS type (91.3\%). Most of the patients $(68.7 \%)$ had mild MS and blacks presented worse prognosis compared to other patients. The average Expanded Disability Score Scale (EDSS) of the non-Caucasian MS patients studied was twice that of Caucasian MS patients (44).

CCR5-432 polymorphisms in Brazil. The studies of the CCR5 genotypes were carried out in unrelated healthy and HIV-1 infected individuals from different Brazilian regions. In an investigation of the urban Brazilian population, the frequencies of normal CCR5/CCR5 homozygous and CCR5/ 332 heterozygous individuals were $93.0 \%$ and $7.0 \%$, respectively, resulting in an allelic frequency of 0.035 ; and no homozygous CCR5- $\triangle 32$ individual was detected (45). Further, the absence of CCR5- $\triangle 32$ was observed in 300 Amerindians from four Brazilian Amazon tribes. All the individuals were homozygous for the normal allele, which correlates to the hypothesis that the CCR5- $\triangle 32$ allele has a European origin, and that its occurrence in urban populations in South America is the result of immigration (46).

The frequency of the CCR5- $\Delta 32$ gene deletion in three Brazilian population groups obtained among HIV-1-negative and HIV-1-infected individuals from the Northeastern region was 0.026 and 0.044 , respectively; among German-descended healthy blood donors from the Southern region it was 0.065 ; and the CCR5- $\triangle 32$ gene deletion was absent among individuals of two Amerindian tribes from the Northern region (47). Another study carried out in unrelated healthy individuals from the Southern region of the country, of white, black and brown ethnic groups exhibited frequencies of $0.086,0.038$, and 0.064 , respectively. The frequencies of the heterozygote genotype among whites, blacks and browns were $14.0 \%$, $8.0 \%$, and $13.0 \%$, respectively, and no homozygotes for the CCR5- $\Delta 32$ deletion were detected (48). These data contributed to the establishment of a scenario that shows a North-South gradient and are compatible with the colonization of Brazil, since the Southeastern and Southern regions received the highest numbers of European immigrants during the 19th and early 20th centuries (49-50).

Although the prevalence of MS in the Brazilian population is significant, no information about the frequency of CCR5 polymorphism related to MS resistance and clinical progression is available. The aims of this study were to determine the frequencies of the CCR5 genotypes and the CCR5- $\Delta 32$ allele in patients with $\mathrm{MS}$, and to investigate a possible association of the CCR5- $\triangle 32$ allele with the development and clinical course of MS in Brazilian patients.

\section{Materials and methods}

Study subjects. The protocol was approved by the Institutional Research Ethics Committees of State University of Londrina. The individuals were invited to participate in the study, were informed in detail about the research and a voluntary written consent form was obtained from the subjects enrolled.

A total of 124 unrelated MS patients with the major forms of MS were enrolled from the Outpatient Clinic for MS of University Hospital, State University of Londrina, Londrina, Southern Brazil. Among them, 98 patients had RR-MS, 17 had SP-MS, 8 had PP-MS and 1 had clinically isolated syndrome (CIS). All of them were diagnosed with MS according to the criteria established (51-52). The disease progression was assessed clinically using the EDSS (53). Data from clinical, laboratorial, and MRI evaluation were registered in a standard protocol.

The control group was composed of 127 unrelated healthy blood donors of the Blood Bank of University Hospital. All MS patients and controls subjects were from a similar geographical area and were coded anonymously.

CCR5 genetic polymorphism. The genomic DNA was extracted from cryopreserved peripheral blood cells using standard procedures (54) and 100-200 ng of DNA were analyzed by polymerase chain reaction (PCR). The amplification of a fragment with 225 base-pairs was performed using primers for CCR5 (sense 5'-ACC AGA TCT CAA AAA GAA 3' and anti-sense 5' CAT GAT GGT GAA GAT AAG CTT CA $3^{\prime}$ ) as previously reported (22). The DNA samples were amplified with Taq polymerase (Invitrogen ${ }^{\mathrm{TM}}$ Life Technologies, Carlsbad, CA, USA) in the buffer provided, at a final concentration of $1.5 \mathrm{mM} / 1$. PCR conditions comprised 5-min denaturation at $94^{\circ} \mathrm{C}, 35$ cycles of $1 \mathrm{~min}$ at $94^{\circ} \mathrm{C}, 1 \mathrm{~min}$ at $58^{\circ} \mathrm{C}$, $1 \mathrm{~min}$ at $72^{\circ} \mathrm{C}$, and 10 -min elongation at $72^{\circ} \mathrm{C}$ in a Hybaid Sprint $^{\mathrm{TM}}$ Thermocycler (Biosystems, Barcelona, Spain). The PCR products were analyzed by $3 \%$ agarose gel electrophoresis and visualized by UV fluorescence after staining with ethidium 
bromide. Ambiguous results were resolved by performing electrophoresis of the products of PCR in a $10 \%$ acrylamide gel, and the gel was stained with silver. The normal allele was detected as a 225 base-pair fragment; the CCR5- $\Delta 32$ allele was detected as 193 base pairs. The images of the gel were captured and recorded with the Digit-Doc-It Program version 1.1.25. Negative and positive controls were included in all the PCR amplifications and electrophoresis performed.

Statistical analysis. A database with the results was set up using the Excel Program. Allelic and genotype frequencies of CCR5 were compared between MS patients and controls, using Fisher's exact test, the chi-square test, or the MannWhitney test. The odds ratio (OR) was calculated by comparing the distributions of alleles and genotypes between healthy subjects and the MS patients. Differences between groups were considered to be statistically significant when $\mathrm{p}<0.05$.

\section{Results}

Profile of subjects studied. Of the 124 MS patients, 85 (68.5\%) were females and $43(31.4 \%)$ were males (female:male ratio $=2.18)$. Of the control group, $56(44.1 \%)$ were females and $71(55.9 \%)$ were males (female:male ratio $=0.79)$. The mean $( \pm \mathrm{SD})$ age of the MS patients was $44.2( \pm 11.9)$ years old, ranging from $18-79$ years old. The mean age $( \pm \mathrm{SD})$ of the control group was $30.0( \pm 10.1)$ years old, ranging from 18.2 to 59.8 years old.

CCR5 genetic polymorphism. Fig. 1 shows the fragments obtained in the PCR according to the CCR5 genotypes observed. The frequency of the genotypes in $124 \mathrm{MS}$ patients from Southern Brazil was 112 (90.3\%) wild-type CCR5/CCR5, and $12(9.6 \%)$ heterozygous CCR5/CCR5- $\Delta 32$. No patient with MS was homozygote for the allele CCR5- $\Delta 32$. The overall frequency of CCR5- $\Delta 32$ among the MS patients was 0.0484 $(4.8 \%)$. The frequency of the genotypes in 127 healthy controls was 115 (90.5\%) wild-type CCR5-CCR5, 10 (7.9\%) heterozygotes, and $2(1.6 \%)$ homozygotes for the deletion CCR5$\Delta 32$. The overall frequency of CCR5- $\triangle 32$ among healthy controls was 0.0055 (5.5\%). There was no significant difference

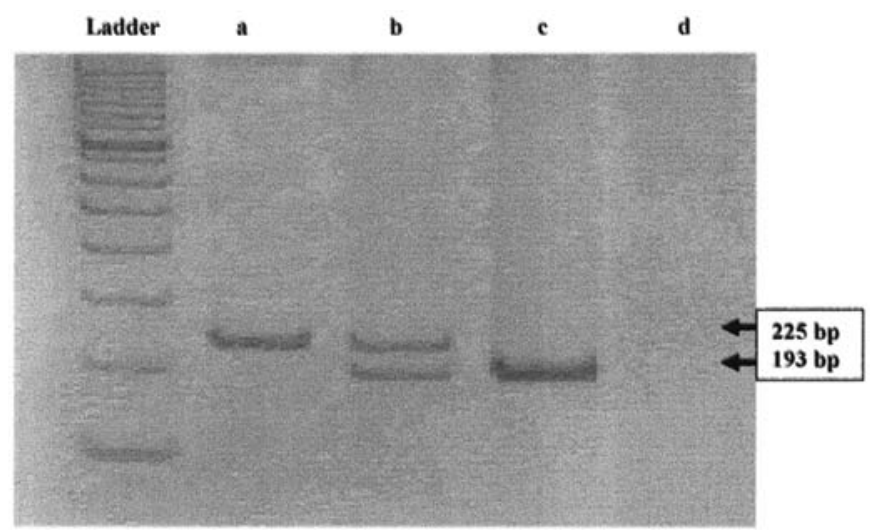

Figure 1. Polymerase chain reaction products of the CCR5 gene evaluated by $10 \%$ acrylamide electrophoresis gel stained with silver. L, ladder of 100 base pairs; a, wild-type genotype (CCR5/CCR5); b, heterozygous genotype (CCR5/CCR5- $\Delta 32)$; c, homozygous genotype (CCR5- $\Delta 32 / C C R 5-\Delta 32)$; $\mathrm{d}$, negative control.

in the distribution of CCR5 genotypes between MS patients and the control group (chi-square test, $\mathrm{p}=0.7337$ ). In the control subjects, the genotype frequencies conformed to Hardy-Weinberg expectations (Table I).

Table II shows the relevant demographic and clinical characteristics for the MS patients enrolled, according to the CCR5 genetic polymorphism. The distribution of the genotypes was statistically significant according to the sex of the MS patients evaluated $(\mathrm{p}=0.0093)$. Although the MS patients with the heterozygous genotype showed lower age at onset of the disease, the difference was not statistically significant (Mann Whitney test, $\mathrm{p}=0.1312$ ).

To evaluate the association between the CCR5 gene polymorphism and the clinical course of MS, one patient (0.8\%) with the CIS was excluded from the statistical analysis. Among the other 123 MS patients with RR, SP, and PP types of MS, there was no association between the CCR5 gene polymorphisms and the clinical course (Fisher's exact test, $\mathrm{p} \cong 1.000$ ). The patients with MS that were heterozygous for the allele CCR5- $\triangle 32$ tended to have prolonged duration of the disease, compared with individuals with a fully functional

Table I. Frequency of the CCR5 genetic polymorphism in healthy individuals (control group) and in patients with multiple sclerosis (MS), from Southern Brazil.

\begin{tabular}{|c|c|c|c|c|c|}
\hline \multirow[b]{2}{*}{$\begin{array}{l}\text { Group } \\
\text { (n) }\end{array}$} & \multicolumn{3}{|c|}{ CCR5 genotype frequency } & \multirow{2}{*}{$\begin{array}{l}\text { Allele frequency } \\
\text { CCR5- } 132 \\
(\%)\end{array}$} & \multirow[b]{2}{*}{$\begin{array}{l}\text { Odds ratio } \\
(95 \% \mathrm{CI})\end{array}$} \\
\hline & $\begin{array}{c}\text { CCR5/CCR5 } \\
\mathrm{n}(\%)\end{array}$ & $\begin{array}{c}\text { CCR5/CCR5- } \Delta 32 \\
\mathrm{n}(\%)\end{array}$ & $\begin{array}{c}\mathrm{CCR} 5-\Delta 32 / \mathrm{CCR} 5-\Delta 32 \\
\mathrm{n}(\%)\end{array}$ & & \\
\hline Control (127) & $115(90.5)$ & $10(7.9)$ & $02(1.6)$ & $0.055(5.5)$ & 1.00 (reference) \\
\hline MS patients (124) & $112(90.3)$ & $12(9.6)$ & $00(0.0)$ & $0.0484(4.8)$ & $1.15(0.49-2.71)$ \\
\hline Total (251) & $227(90.4)$ & $22(9.1)$ & $02(0.9)$ & $0.0517(5.2)$ & \\
\hline
\end{tabular}

Control: healthy blood donors from the Blood Bank of University Hospital of Londrina, Londrina, Paraná, Brazil. MS patients: at the Outpatient Clinic of Neurology of the State University of Londrina, Londrina, Paraná, Brazil. CCR5/CCR5, without mutation; CCR5/CCR5$\Delta 32$, mutation in heterozygosity; CCR5- $\Delta 32 / C C R 5-\Delta 32$, mutation in homozygosity; CI, confidence interval; chi-square test $\chi^{2}=0.1$, with 1 value, degree of freedom of $\mathrm{p}=0.7337$. 
Table II. Demographic and clinical characteristics of patients with multiple sclerosis from Southern Brazil, according to the CCR5 genetic polymorphism.

\begin{tabular}{|c|c|c|c|c|}
\hline Characteristic & $\begin{array}{c}\text { Genotype } \\
\text { CCR5/CCR5 }\end{array}$ & $\begin{array}{c}\text { Genotype } \\
\text { CCR5/CCR5- } \triangle 32\end{array}$ & Total & $\mathrm{p}$ value \\
\hline Number of patients (\%) & $112(90.3)$ & $12(9.6)$ & $124(100)$ & \\
\hline \multicolumn{5}{|l|}{ Sex } \\
\hline Female, n (\%) & $81(72.3)$ & $4(33.3)$ & $85(68.5)$ & \multirow[t]{2}{*}{0.0093} \\
\hline Male, n (\%) & $31(27.7)$ & $8(66.7)$ & $39(31.5)$ & \\
\hline \multicolumn{5}{|l|}{ Age (years) } \\
\hline Range & $18.0-79.0$ & $26.0-62.0$ & $18.0-79.0$ & \multirow{2}{*}{0.5454} \\
\hline Mean \pm SD & $44.3 \pm 11.9$ & $42.6 \pm 12.2$ & $44.2 \pm 11.9$ & \\
\hline \multicolumn{5}{|c|}{ Age at disease onset (years) } \\
\hline Range & $10.0-68.0$ & $18.0-53.0$ & $10.0-68.0$ & \multirow[t]{2}{*}{$0.1312^{\prime}$} \\
\hline Mean $\pm \mathrm{SD}$ & $36.6 \pm 12.0$ & $31.7 \pm 11.1$ & $36.2 \pm 11.9$ & \\
\hline \multicolumn{5}{|c|}{ Duration of the disease (years) } \\
\hline Range & $5.6-30.0$ & $0.25-44.0$ & $0.25-44.0$ & \multirow[t]{2}{*}{$0.8422^{\prime}$} \\
\hline Mean \pm SD & $7.7 \pm 5.6$ & $11.2 \pm 12.9$ & $8.0 \pm 6.7$ & \\
\hline \multicolumn{5}{|l|}{ Clinical forms } \\
\hline Relapsing-remitting & 88 (78.6) & $10(83.3)$ & $98(79.0)$ & \multirow[t]{4}{*}{$\cong 1.000^{\mathrm{a}}$} \\
\hline Secondary progressive & $16(14.3)$ & $01(8.3)$ & $17(13.7)$ & \\
\hline Primary progressive & $07(6.3)$ & $01(8.3)$ & $08(6.5)$ & \\
\hline $\mathrm{CIS}^{\mathrm{c}}$ & $01(0.9)$ & $0(0.0)$ & $01(0.8)$ & \\
\hline \multicolumn{5}{|l|}{ Incapacity scale (EDSS) ${ }^{\mathrm{d}}$} \\
\hline Range & $0.0-8.0$ & $1.0-4.5$ & $0.0-8.0$ & \multirow[t]{2}{*}{0.9796} \\
\hline Mean \pm SD & $2.7 \pm 2.2$ & $2.4 \pm 1.2$ & $2.6 \pm 2.1$ & \\
\hline Incapacity scale (EDSS) & $\mathrm{n}=112(\%)$ & $\mathrm{n}=12(\%)$ & $\mathrm{n}=124(\%)$ & \multirow{3}{*}{$0.2101^{*}$} \\
\hline$<6.0$ & $93(83.0)$ & $12(100.0)$ & $105(84.7)$ & \\
\hline$\geq 6.0$ & $19(17.0)$ & $0(0.0)$ & $19(15.3)$ & \\
\hline Patients with EDSS $<6.0$ & $\mathrm{n}=93(\%)$ & $\mathrm{n}=12(\%)$ & $\mathrm{n}=105(\%)$ & \multirow{6}{*}{$1.000^{\mathrm{a}}$} \\
\hline$\leq 10$ years of disease & $72(77.4)$ & $9(75.0)$ & $81(77.1)$ & \\
\hline$>10$ years of disease & $21(22.6)$ & $3(25.0)$ & $24(22.9)$ & \\
\hline Patients with EDSS $\geq 6.0$ & $\mathrm{n}=19(\%)$ & $\mathrm{n}=0(\%)$ & $\mathrm{n}=19(\%)$ & \\
\hline$\leq 10$ years of disease & $9(47.4)$ & $0(0.0)$ & $9(47.4)$ & \\
\hline$>10$ years of disease & $10(52.6)$ & $0(0.0)$ & $10(52.6)$ & \\
\hline
\end{tabular}

a, Fisher's exact test; b, Mann-Whitney test; c, clinically isolated syndrome. The patient of this clinical form was excluded for the statistical analysis; $d$, expanded disability score scale.

CCR5, with 11.2 years and 7.7 years, respectively. However, this difference was also not statistically significant (MannWhitney test, $\mathrm{p}=0.8422$ ).

The MS patients with the CCR5- $\Delta 32$ allele presented lower EDSS values compared with MS patients with the CCR5 wildtype genotype. However, the difference was not statistically significant (Mann-Whitney test, $\mathrm{p}=0.9796$ ). When the disease progression was evaluated according to the CCR5 genotypes, all the $12 \mathrm{MS}$ patients with the CCR5- $\Delta 32$ allele presented EDSS $<6$. Of these, three $(25.0 \%)$ had more than ten years of disease duration. Among the MS patients with the CCR5 wild-type genotype, $21(22.6 \%)$ had more than ten years of disease duration. However, the difference observed was also not statistically significant (Fisher's exact test, $\mathrm{p}=1.000$ ).
MRI findings. Table III shows the MRI results obtained in 42 MS patients. The MRI findings in MS patients with the CCR5- $\triangle 32$ genotype exhibited predominant periventricular distribution and ovoid appearance. Of 20 MS patients with positive gadolinium-enhancing imaging, 19 (63.0\%) were CCR5 wild-type and one $(8.3 \%)$ was a CCR5- $\triangle 32$ carrier (chi-square test, $\mathrm{p}=0.0013$ ). Brain atrophy was observed in 10 MS patients with CCR5 wild-type genotype and in one $(8.3 \%)$ with the mutated allele (Fisher's exact test, $\mathrm{p}=0.1333$ ).

\section{Discussion}

This is the first study undertaken to determine the frequency of the CCR5- $\triangle 32$ allele in a sample of MS patients from the 
Table III. Magnetic resonance imaging (MRI) findings observed in 42 patients with multiple sclerosis from Southern Brazil, according to the CCR5 genetic polymorphism.

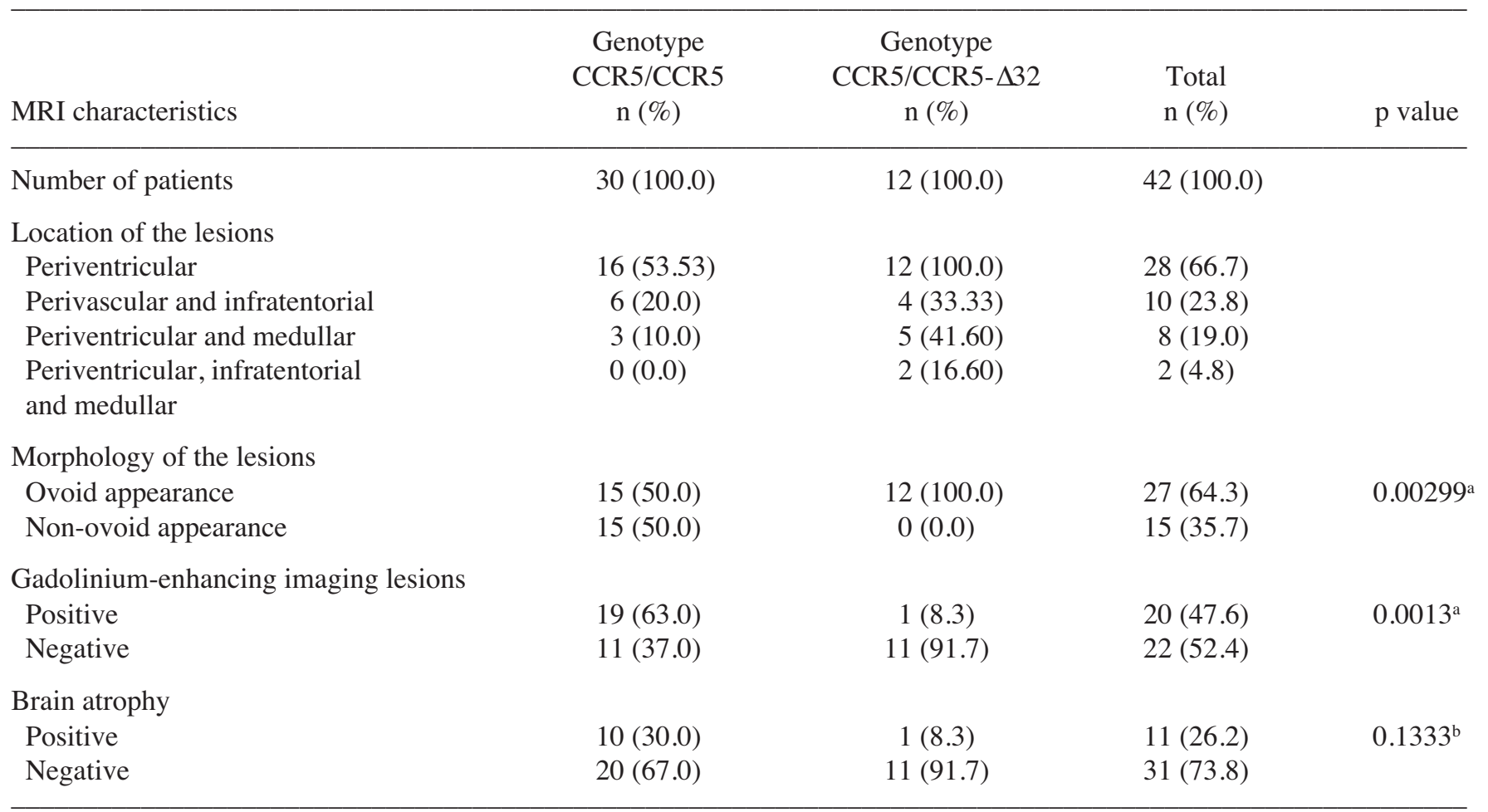

${ }^{\mathrm{a} C h i}$-square test; ${ }^{\mathrm{b}}$ Fischer's exact test.

Brazilian population. The overall frequencies of the CCR5 genotypes and the CCR5- $\Delta 32$ allele obtained either for the total sample or for the healthy control subjects were consistent with data reported for other healthy populations. These results also confirm the variable distribution of the CCR5 polymorphism reported by previous studies $(22,23)$.

The CCR5- $\triangle 32$ allelic frequency of 0.055 (5.5\%) obtained among the control group and of 0.045 (4.5\%) among the MS patients can be explained by the heterogeneous ethnic structure of the Brazilian population. Southern and Mediterranean Europeans (Portuguese, Italian and Middle Eastern), Asians, Arabians, Africans, and Native Amerindians have contributed to the formation of the present Brazilian population since the 16 th century (49-50). The results were also consistent with the first evidence for the contribution of the CCR5- $\Delta 32$ allele to the genetic background of the urban Brazilian population, which confirmed the intense ethnic admixture (45).

The higher number of women than men among the MS patients enrolled in this study is in agreement with the epidemiological characteristics of MS. The fact that women with the disease outnumber men with MS confirms hormonal variables as a risk factor. The precise mechanisms by which sex hormones may influence MS susceptibility have not been totally clarified, but the stimulatory effects of estrogens on inflammatory cytokine secretion and the reverse by androgens probably represent one important mechanism $(55,56)$.

The CCR5 genotypes and the CCR5- $\Delta 32$ allele frequencies did not differ significantly among the groups evaluated. The distribution of CCR5- $\Delta 32$ genotypes obtained in this study is comparable to previous studies suggesting that these results are not due to a difference in overall distribution of genotypes $(12,35,36,38,57)$. These results are consistent with findings in other previous reports which showed that the CCR5- $\triangle 32$ allele has little or no effect on the development of MS $(12,34,36,38,57)$. This would further imply the redundancy in the chemokine system, and the CCR5 ligand must be assumed to function through other closely related chemokine receptors (37).

Being a carrier for CCR5- $\triangle 32$ was associated with lower recurrence rate with slower progression $(12,35)$ and relatively late age of onset of MS (34). In other studies, however, the deletion was not associated with long-term disability $(38,57)$, nor with age of onset of MS $(35,57)$.

The MRI findings showed that the gadolinium enhancement was lower in MS patients with the CCR5- $\Delta 32$ allele, reflecting a lower clinical activity of the disease. Brain MRI was abnormal in 70-95\% of patients with definitive MS and the gadolinium enhancement correlated with the clinical activity of the disease and corresponded anatomically with the symptoms and signs (58). The evaluation of gadoliniumenhancing lesions is one MS MRI criteria for demyelination in time and space $(51,52)$. A positive MRI gadolinium enhancement indicated an ongoing inflammation and activity of the MS process, whereas gadolinium negative imaging should be considered as a sign of stabilization of the MS process (59).

Despite the absence of any significant difference for age of onset and the duration of the disease between carriers versus non-carriers of CCR5- $\triangle 32$ in the MS patients evaluated, the MS patients with the CCR5- $\Delta 32$ allele had an older age 
of onset of disease, showed lower gadolinium enhancement and brain atrophy in the MRI findings, suggesting that the association between the CCR5- $\Delta 32$ and disease variables can not be excluded.

Taken together, the results underscore that the CCR5- $\Delta 32$ polymorphism is not a major determinant of susceptibility to develop MS and, by itself, may not be sufficient to prevent the disease progression in the population under study. However, this gene factor may potentially exert additive or synergistic influence with other factors, such as the immune response mediated by $\mathrm{CD}^{+}$Th 1 cells, the levels of inflammatory cytokines and chemokines in the CSF, the chemokine receptor expression (14,60-61), as well as the human leukocyte antigen (HLA) and apolipoprotein E polymorphisms $(1,33)$ and the polymorphism of IL-10 cytokine promoter (57). Microsatellite polymorphisms in CCL7 (MCP3) have also been associated with disease resistance to MS (1).

At the moment, there is no biomarker available that fulfils the criteria of a surrogate endpoint in MS. However, some of them may prove extremely useful in defining disease heterogeneity and thus stratifying patients into distinct subgroups. The establishment of biomarkers that reflect dysfunction or imbalance of the immune response would be essential in studying disease heterogeneity and assessing how different phenotypes correlate with or allow the prediction of the response to novel process-specific therapies. In addition to the antibodies, the complement-related biomarkers, the adhesion molecules, the cytokines and chemokines and their receptors are process-specific biomarkers proposed in MS that reflect the alteration of the immune system. CCR5 is suggested as a candidate biomarker of Th1 cells and may aid in studying disease heterogeneity and the therapy response (62).

Since in the present study approximately $90.3 \%$ of MS patients evaluated were homozygous for the wild-type CCR5 gene, further studies comprising larger numbers of individuals carrying non-wild-type haplotypes are needed to determine CCR5- 432 involvement in the specific process of MS pathology and pathogenesis.

\section{Acknowledgments}

We thank the State University of Londrina, and the University Hospital of Londrina, for technical and administrative support, the School of Medicine of Ribeirão Preto, University of São Paulo for technical and scientific support, and the HUTEC for the financial support.

\section{References}

1. Sospedra M and Martin R: Immunology of Multiple Sclerosis. Ann Rev Immunol 23: 683-747, 2005.

2. McFarland HF: Correlation between MR and clinical findings of disease activity in multiple sclerosis. Am J Neuroradiol 20: 1777-1778, 1999.

3. Raine CS and Scheinberg LC: On the immunopathology of plaque development and repair in multiple sclerosis. J Neuroimmunol 20: 189-201, 1988.

4. Lucchinetti C, Bruck W, Parisi J, Scheithauer B, Rodriguez M and Lassmann $\mathrm{H}$ : Heterogeneity of multiple sclerosis lesions: implications for the pathogenesis of demyelination. Ann Neurol 47: 707-717, 2000.

5. Coo $\mathrm{H}$ and Aronson KJ: A systematic review of several potential non-genetic risk factors for multiple sclerosis. Neuroepidemiology 23: 1-12, 2004.
6. Bitsch A, Kuhlmann T, Da Costa C, Bunkowski S, Polak T and Bruck W: Tumor necrosis factor $\alpha$ mRNA expression in early multiple sclerosis lesions: correlation with demyelinating activity and oligodendrocyte pathology. Glia 29: 366-375, 2000.

7. Nakashima I, Fujihara K, Misu T, Okita N, Takase S and Itoyama Y: Significant correlation between IL-10 levels and $\mathrm{IgG}$ indices in the cerebrospinal fluid of patients with multiple sclerosis. J Neuroimmunol 111: 64-67, 2000.

8. Simpson J, Rezaie P, Newcombe J, Cuzner ML, Male D and Woodroofe MN: Expression of the $\beta$-chemokine receptors CCR2, CCR3 and CCR5 in multiple sclerosis central nervous system tissue. J Neuroimmunol 108: 192-200, 2000.

9. Szczucinski A and Losy J: Chemokines and chemokine receptors in multiple sclerosis. Potential targets for new therapies. Acta Neurol Scand 115: 137-146, 2007.

10. Gonzales-Amaro R and Sanches-Madrid F: Intercellular adhesion molecules and chemotaxic factors in the pathogenesis of multiple sclerosis. Rev Neurol 35: 985-993, 2002.

11. Sindern E: Role of chemokines and their receptors in the pathogenesis of multiple sclerosis. Front Biosci 9: 457-463, 2004.

12. Sellebjerg F, Madsen HO, Jensen CV, Jensen J and Garred P: CCR5-delta32, matrix metalloproteinase- 9 and disease activity in multiple sclerosis. J Neuroimmunol 102: 98-106, 2000.

13. Sorensen TL, Tani M, Jensen J, et al: Expression of specific receptors in the central nervous system of multiple sclerosis patients. J Clin Invest 103: 807-815, 1999.

14. Balashov KE, Rottman JB, Weiner HL and Hancock WW: $\mathrm{CCR}^{+}$and $\mathrm{CXCR}^{+} \mathrm{T}$ cells are increased in multiple sclerosis and their ligands MIP- $\alpha$ and IP-10 are expressed in demyelinating brain lesions. Proc Natl Acad Sci USA 96: 6873-6878, 1999.

15. Bugeja MJ, Booth D, Bennetts B, Heard R, Rubio J and Stewart G: An investigation of polymorphisms in the 17q11.2$12 \mathrm{CC}$ chemokine gene cluster for association with multiple sclerosis in Australians. BMC Med Genetic 7: 64, 2006.

16. Mäurer M, Kruse N, Giess R, Kyriallis K, Toyka KV and Rieckmann P: Gene polymorphism at position -308 of the tumor necrose factor $\alpha$ promoter is not associated with disease progression in multiple sclerosis. J Neurol 246: 949-954, 1999.

17. Mycko M, Kowalski W, Kwinkowski M, et al: Multiple sclerosis: the frequency of allelic forms of tumor necrosis factor and lymphotoxin-alpha. J Neuroimmunol 84: 198-206, 1998.

18. Fernandez-Arquero M, Arroyo R, Rubio A, et al: Primary association of a TNF gene polymorphism with susceptibility to multiple sclerosis. Neurology 53: 1361-1363, 1999.

19. Lucotte G, Bathelier C and Mercier G: TNF-alpha polymorphisms in multiple sclerosis: no association with -238 and -308 promoter alleles, but the microsatellite allele a11 is associated with the disease in French patients. Mult Scler 6: 78-80, 2000.

20. Weber A, Wandinger K-P, Mueller W, et al: Identification and functional characterization of a highly polymorphic region in the human TRAIL promoter in multiple sclerosis. J Neuroimmunol 149: 195-201, 2004

21. Ehling R, Gassner Ch, Lutterotti A, et al: Genetic variants in the tumor necrosis factor receptor II gene in patients with multiple sclerosis. Tissue Antigens 63: 28-33, 2004.

22. Dean M, Carrington M, Winkler C, et al: Genetic restriction of HIV-1 infection and progression to AIDS by a deletion allele of the CKR5 structural gene. Science 273: 1856-1862, 1996.

23. Liu R, Paxton WA, Choe S, et al: Homozygous defect in HIV-1 coreceptor accounts for resistance of some multiply-exposed individuals to HIV-1 infection. Cell 86: 367-377, 1996.

24. Samsom M, Libert F, Doranz BJ, et al: Resistance to HIV-1 infection in Caucasian individuals bearing mutant alleles of the CCR-5 chemokine receptor gene. Nature 382: 722-725, 1996.

25. Martinson JJ, Chapman NH, Rees DC, Liu YT and Clegg JB: Global distribution of the CCR5 gene 32 base-pair deletion. Nat Genet 16: 100-103, 1997.

26. Voevodin A, Samilchuk E and Dashti S: A survey for 32 nucleotide deletion in the CCR-5 chemokine receptor gene (deltaccr-5) conferring resistance to human immunodeficiency virus type 1 in different ethnic groups and in chimpanzees. $\mathbf{J}$ Med Virol 55: 147-151, 1998.

27. Libert F, Cochaux P, Beckman G, et al: The delta CCR5 mutation conferring protection against HIV-1 in Caucasian population has a single and recent origin in Northeastern Europe. Hum Mol Genet 7: 399-406, 1998.

28. Lucotte G and Mercier G: Distribution of the CCR5 gene 32-bp deletion in Europe. J Acquir Immun Defic Syndr Hum Retrovirol 19: 174-177, 1998. 
29. Battiloro E, Andreoni M, Parisi SG, et al: Distribution of the CCR5 delta 32 allele in Italian HIV type 1-infected and normal individuals. AIDS Res Hum Retroviruses 16: 181-182, 2000.

30. Struyf F, Thoelen I, Charlier N, et al: Prevalence of CCR5 and CCR2 HIV-coreceptor gene polymorphisms in Belgium. Hum Hered 50: 304-307, 2000.

31. Lucotte G: Distribution of the CCR5 gene 32-basepair deletion in West Europe. A hypothesis about the possible dispersion of the mutation by the Vikings in historical times. Hum Immunol 62: 933-936, 2001.

32. Roman F, Franck N, Burgy C, et al: Prevalence of HIV coreceptor polymorphism in HIV-infected patients and uninfected volunteers in Luxembourg. HIV Clin Trials 3: 195-201, 2002.

33. Schreiber K, Otura AB, Ryder LP, et al: Disease severity in Danish multiple sclerosis patients evaluated by MRI and three genetic markers (HLA-DRB1*1501, CCR5 deletion mutation, apolipoprotein E). Mult Scler 8: 295-298, 2002.

34. Barcellos LF, Schito AM, Rimmler JB, et al: CC-chemokine receptor 5 polymorphism and age of onset in familial multiple sclerosis. Multiple Sclerosis Genetics Group. Immunogenetics 51: 281-288, 2000.

35. Kantor R, Bakhanashvili M and Achiron A: A mutated CCR5 gene may have favorable prognostic implications in MS. Neurology 61: 238-240, 2003.

36. Bennetts BH, Teutsch SM, Buhler MM, Heard RN and Stewart GJ: The CCR5 deletion mutation fails to protect against multiple sclerosis. Hum Immunol 58: 52-59, 1997.

37. Pulkkinen K, Luomala M, Kuusisto $\mathrm{H}$, et al: Increase in CCR5 Delta32/Delta32 genotype in multiple sclerosis. Acta Neurol Scand 109: 342-347, 2004.

38. Silversides JA, Heggarty SV, McDonnell GV, Hawkins SA and Graham CA: Influence of CCR5 delta 32 polymorphism on multiple sclerosis susceptibility and disease course. Mult Scler 10: 149-152, 2004.

39. Gade-Andavolu R, Comings DE, MacMurray J, et al: Association of CCR5 delta 32 deletion with early death in multiple sclerosis. Genet Med 6: 126-131, 2004.

40. Papais-Alvarenga RM, Alves-Leon SV, Santos CMM, et al: South Atlantic project: a Brazilian multiple sclerosis trial. In: Esclerosis Multiple: Una Mirada Ibero Pan Americana. Arriagada RC and Nogales-Gaete J (eds). Arrynog Ediciones, Santiago, pp35-45, 2002.

41. Ferreira MLB, Machado MIM, Vilela ML, et al: Epidemiologia de 118 casos de esclerose múltipla com seguimento de 15 anos no Centro de Referência do Hospital da Restauração de Pernambuco. Arq Neuropsiquiatr 62: 1027-1032, 2004.

42. Kaimen-Maciel DR, Medeiros M, Pistori R, Biaggio C, Rocha F and Garcia-Lopes LH: The prevalence of multiple sclerosis in two cities in the north of Paraná State - Brazil. Mult Scler 10 (suppl 2): S158, 2004.

43. Kaimen-Maciel DR, Frota EC, Brum-Souza D and Barreira A: Multiple Sclerosis in reference centers of three Brazilian cities in Minas Gerais, São Paulo and Paraná States. Rev Neurol 43: $15,2006$.

44. Cardoso E, Fukuda TG, Pereira J, et al: Clinical and epidemiological profile of multiple sclerosis in a reference center in the state of Bahia, Brazil. Arq Neuropsiquiatr 64: 727-730, 2006.
45. Passos GA Jr and Picanco VP: Frequency of the delta CCR5 deletion allele in the urban Brazilian population. Immunol Lett 61: 205-207, 1998.

46. Leboute APM, Carvalho MWO and Simões AL: Absence of the delta CCR5 mutation in indigenous populations of the Brazilian Amazon. Hum Genet 105: 442-443, 1999.

47. Grimaldi R, Shindo N, Acosta AX, et al: Prevalence of the CCR5- $\triangle 32$ mutation in Brazilian populations and cell susceptibility to HIV-1. Hum Genet 111: 102-104, 2002.

48. Vargas AE, Marrero AR, Zalzano FM, Bortolini MC and Chies JAB: Frequency of CCR5- $\triangle 32$ in Brazilian populations. Braz J Med Biol Res 39: 321-325, 2006.

49. Alves-Silva J, Santos MS, Guimarães PEM, et al: The ancestry of Brazilian mtDNA lineages. Am J Hum Genet 67: 444-461, 2000 .

50. Mikawa AY, Tagliavini SA and Costa PI: CCR5 genotype and plasma B-chemokine concentration of Brazilian HIV-infected individuals. Braz J Med Biol Res 35: 1333-1337, 2002.

51. McDonald WI, Compston A, Edan G, et al: Recommended diagnostic criteria for multiple sclerosis: guidelines from the International Panel on the diagnosis of multiple sclerosis. Ann Neurol 50: 121, 2001.

52. Polman CH, Reingold SC, Edan G, et al: Diagnostic criteria for multiple sclerosis: 2005 revisions to the 'McDonald Criteria'. Ann Neurol 58: 840-846, 2005.

53. Kurtze JF: Clinical definition for multiple sclerosis treatment trials. Ann Neurol 36: 73-79, 1994.

54. Miller AS, Dykes DD and Polesky HS: A simple salting out procedure for extraction DNA from human nucleated cells. Nucleic Acid Res 16: 1215-1219, 1988.

55. Runmarker B and Andersen O: Pregnancy is associated with a lower risk of onset and a better prognosis in multiple sclerosis. Brain 118: 253-261, 1995.

56. Sicotte NL, Liva SM, Klutch R, et al: Treatment of multiple sclerosis with the pregnancy hormone estriol. Ann Neurol 52: 421-428, 2002.

57. Luomala M, Lehtimaki T, Huhtala $\mathrm{H}$, et al: Promoter polymorphism of IL-10 and severity of multiple sclerosis. Acta Neurol Scand 108: 396-400, 2003.

58. Gonzalez-Scarano F, Grossman RI, Galetta S, Atlas SW and Silberberg DH: Multiple sclerosis disease activity correlates with gadolinium-enhanced magnetic resonance imaging. Ann Neurol 21: 300-306, 1987.

59. Michalowska-Wender G and Wender M: Mononuclear subsets in the peripheral blood of multiple sclerosis patients in relation to results of brain gadolinium-enhancing imaging. Folia Neuropathol 44: 67-71, 2006.

60. Martinez-Caceres EM, Espejo C, Brieva L, et al: Expression of chemokine receptors in the different clinical forms of multiple sclerosis. Mult Scler 8: 390-395, 2002.

61. Lucchinetti CF: CCR5- $\triangle 32$ polymorphism effects on CCR5 expression, patterns of immunopathology and disease course in multiple sclerosis. J Neuroimmunol 169: 137-143, 2005.

62. Bielekova B and Martin R: Development of biomarkers in multiple sclerosis. Brain 127: 1463-1478, 2004. 